\title{
Design of Highly Secured Biometric Voting System
}

\author{
N. Narayanan, Ch. Surya Pradeep, Piyush Gulati, G. Raj Bharath, S.Nivash
}

\begin{abstract}
Voting is the most basic right of every citizen and is one of the most important responsibilities of every citizen. The votes which we cast decide the future of our country, and we must vote honestly and not succumb to any sort of pressure as the phrase goes "With great power comes great responsibility". Now once our votes are cast, we should ensure they are not manipulated in any way. The current voting system (EVM) is easy to manipulate i.e., there is a lot of human intervention which in turn could compromise the results of the elections, hence in this project we will try to solve this vulnerability by introducing a two-step verification which will help avoid the middle man attack i.e. only when the voter is physically present the fingerprint of the voter can be registered and only then the OTP will be sent to user's mobile number this in turn prevents fake voters.
\end{abstract}

Keywords: EVM, Arduino, Fingerprint Scanning, OTP, Biometrics, GSM, Aadhaar

\section{INTRODUCTION}

The project employs the concept of two step verification which ensures that our votes are cast to person of our choice. Biometrics or bio signatures like fingerprint andiris are unique features of every individual. Hence, we use biometrics for this very important responsibility. Once verified it employs with second step, that is it sends OTP to the registered mobile number of the user and only when the user enters the OTP the user is allowed to vote and is registered. Now for the OTP system to work we use the Aadhaar data collected by the government. This copy of the data could be stored on the voting machine or cloud server, and once the vote is cast, the user's data is removed from storage, hence the same person cannot vote again. This system will enable the Parliament and the State elections to be conducted on the same day, also since this system involves biometric verification this module can be installed in any ATMs or KYC centres across the country which will increase the polling rate by a significant margin as almost every village nowadays has a KYC centre. ATM's also have adopted to growing trend of using bio-signatures for secure transactions hence almost every ATM in the country currently houses a fingerprint module which are very precise this will also prevent people mobbing at voting stations and will greatly reduce the voting station tension.

\section{PROPOSED SYSTEM}

Our project is focused on using OTP verification for electronic voting machine. Our system can easily identify any voter by getting their fingerprint from the available data of the election commission. Whenever the unit detects a fingerprint, it will match it from the database. With reference to the existing data the biometric verification will be done. The person would get an OTP for verification which needs to be entered by the person for vote casting. Our model can easily

detect any forgery or second voting. The voter can also get himself registered using aadhaar details and his fingerprint. The system would be accessed by password with the administrator. After OTP verification the person would be able to cast the vote and would receive a verification message for to whom he voted. Similar to the existing electronic voting machines, the unit will count votes of every voter. The administrator would be able to view the result as a message after the polling. The major advantage of our proposed system would be time efficiency and accuracy of the result. It would be real time with high accuracy for both identification of the voter and counting votes. Our system is completely offline and limited to the administrator and voter. Which explains, it would be very complex to hack the data. Our model can be represented by a flowchart as shown below.

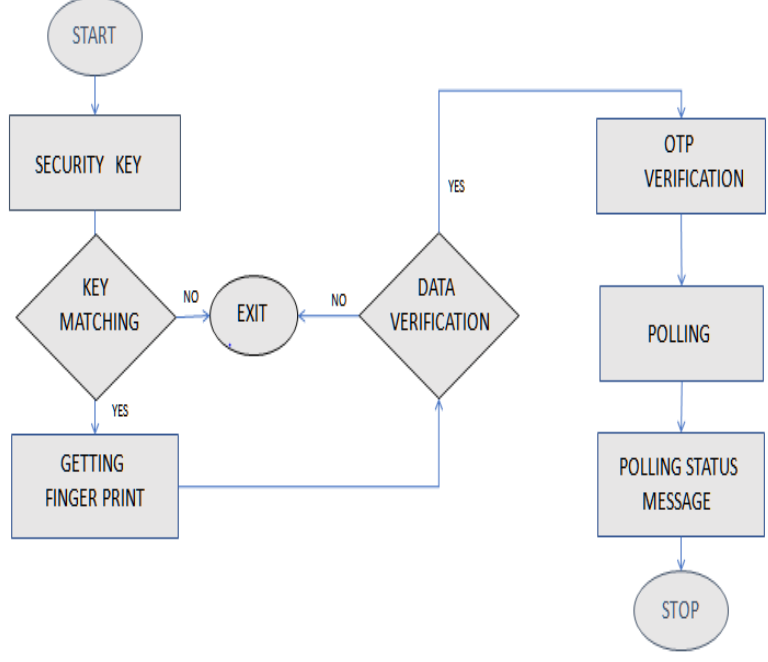

Fig. 1: Flowchart representation of the processes involved

\footnotetext{
Revised Version Manuscript Received on Jun 20, 2019.

N Prashanth Narayanan, B.Tech ECE SRM IST.

Chikkala Surya Pradeep, B.Tech ECE SRM IST.

Piyush Gulat, B.Tech ECE SRM IST.

Gollapudi Raj Bharath, B.Tech ECE SRM IST

S. Nivash, Assistant Professorin School of ECE, SRM Institute of science and tec.
} 


\section{Design of Highly Secured Biometric Voting System}

\section{MODULES}

\section{A. Controller unit}

The controller unit of the whole design is Arduino UNO R3 which is a microcontroller. The board is based on ATMEGA32. The board is combined with the digital and PWM type signals. In our model we would access the fingerprint scanner module using the pulse width modulation pin and one digital pin. The matrix keypad is connected to analog pins. The code to run the set can be downloaded from the computer to Arduino board using USB connector.

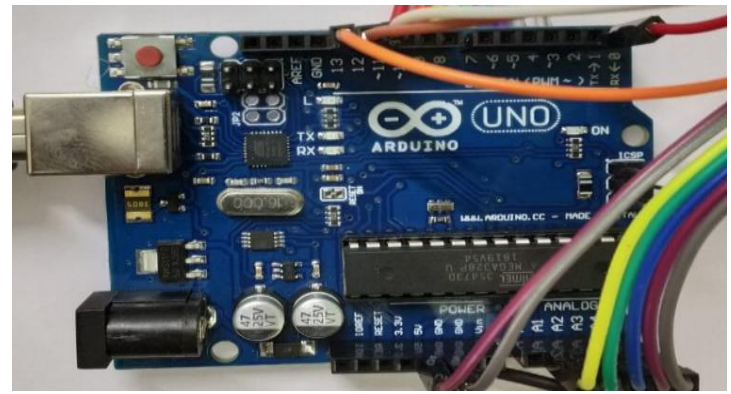

Fig A: Controller unit

\section{B. Fingerprint module}

The fingerprint module used in our model is R307. The fingerprint module, captures the fingerprint and saves it to the memory of the micro controller, it matches the fingerprint of the user with the fingerprint database, it has a 32-bit CPU which interfaces with the Arduino, the 4 external wires helps to send the data to Arduino, and the other 2 wires are voltage and ground wires.

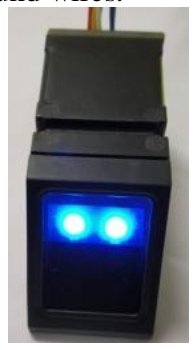

Fig B: Fingerprint module

\section{C.GSM module}

This is a reliable wireless module. The SIM900A is a complete Dual-band GSM/GPRS solution in a SMT module. It is an industry-standard interface, the SIM900A delivers GSM/GPRS 900/1800MHz performance for voice, SMS and data in a small form factor and with low power consumption.

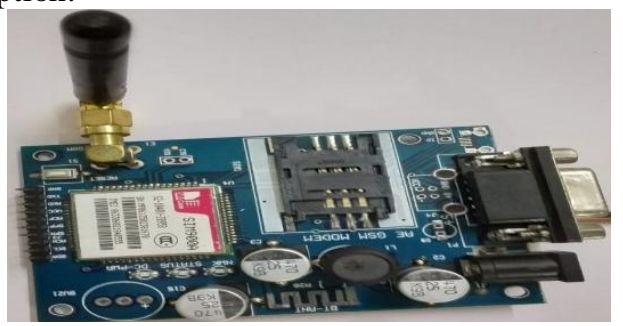

Fig C: GSM module

D. Matrix Keypad $4 x 4$
Each key of the matrix keypad is configurable to suite our needs we have configured each button accordingly.

TABLE I: Keypad Configurations

\begin{tabular}{|c|c|}
\hline KEYS & MAPPED ACTIONS \\
\hline A : Party 1 & Vote registered for party 1 \\
\hline B : Party 2 & Vote registered for party 2 \\
\hline C : Party 3 3 Vote registered for party 3 \\
\hline$\#$ & Vote registered for party 4 \\
\hline$*$ & $\begin{array}{c}\text { Deletes the current database } \\
\text { from the memory. }\end{array}$ \\
\hline & $\begin{array}{c}\text { Send the final result to the } \\
\text { Administrator. }\end{array}$ \\
\hline
\end{tabular}

The 4 wires on the matrix keypad are connected to the 4 analog pins of the Arduino microcontroller, this enables it to communicate with the Arduino.

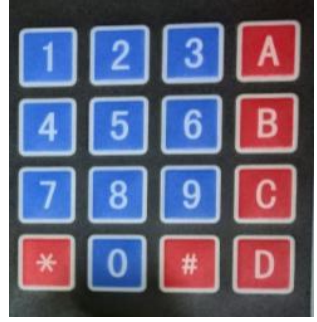

Fig D: Matrix keypad

\section{RESULTS}

Before we proceed to the hardware implementation the above/below figure shows the complete hardware implementation of the proposed new system. The hardware and software were built hand in hand and every module was tested and verified using the respective code snippets. The hardware setup consists of an Arduino UNO micro controller, a fingerprint module which is used to authenticate the voter, a LCD display used to visualize the voting system, a Matrix keypad accept the votes and it acts as one source for the data entry into the system, finally the GSM module which sends the OTP to the voters mobile number when the finger print has been successfully verified. Fig 2 shows the initial startup of the screen where we greeted with a generic startup message and now the system is ready to go. It will now be able to accept votes from the voters and count them.

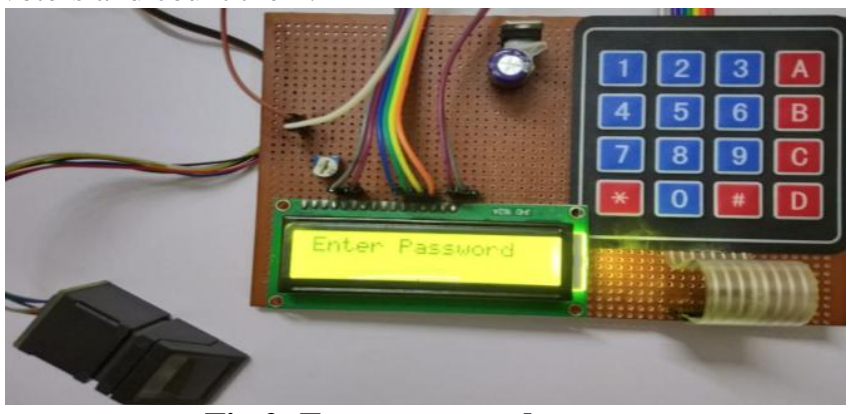

Fig 2: Enter password screen

Fig 3 shows the next state or step of the process.

We would now be using secured password only known to the administrator to unlock the system. Once unlocked the system is ready for polling. Here we try to simulate the database by manually adding the fingerprint through a registration process, in real time this database will serve as a source for user biometric data i.e. the aadhaar card data 
which holds the phone numbers and fingerprints of every citizen in India. After the registration process is complete, we are taken to the voting screen where we are prompted to place our finger to register the fingerprint. Once the fingerprint has been successfully matched the Arduino sends a command to the GSM module to send an OTP to the user. Since the user needs to be physically present to cast their votes illicit voting can be prohibited once the OTP has been received the user will be prompted to enter the above-mentioned OTP.

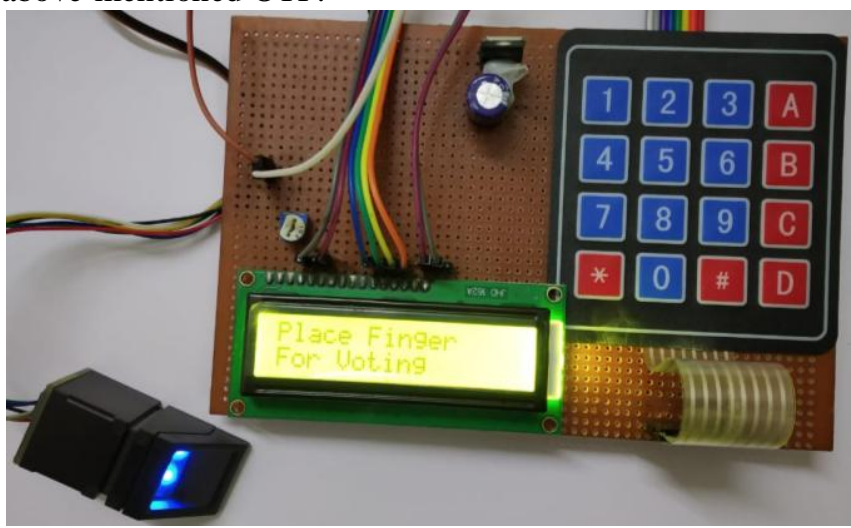

Fig 3: Fingerprint Verification

Fig 4 shows the voting screen, here the user is prompted to vote for one of the registered parties through the matrix keypad.

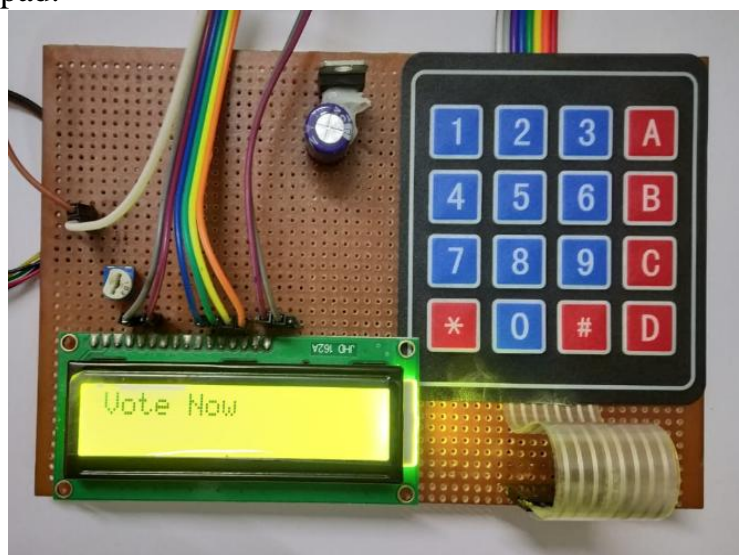

Fig 4: Voting starts

Once the voting process comes to an end the votes can be immediately counted by simple press of a button on the matrix keypad, this will send a message to the administrator through the GSM module.

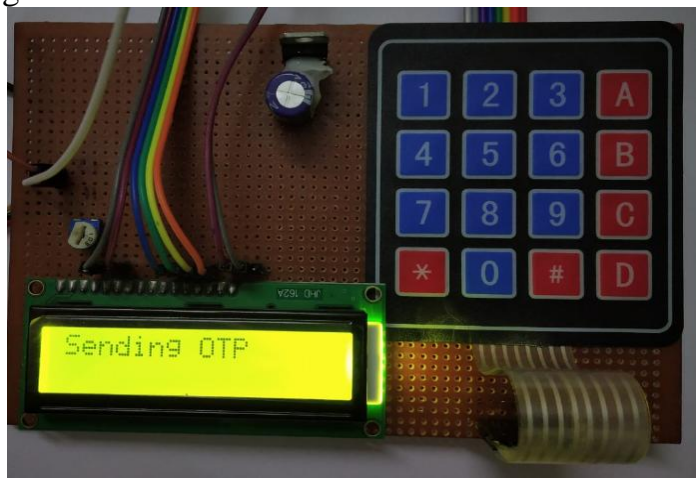

Fig 4a: Sending OTP

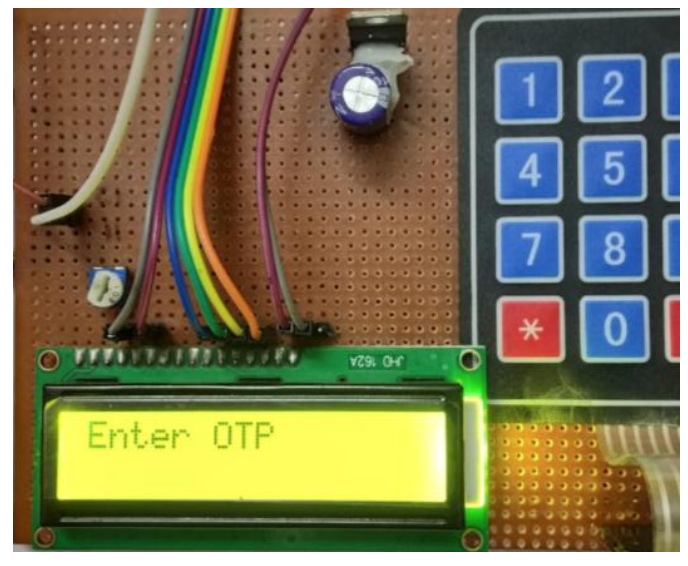

Fig 4b: Enter OTP

Fig 5 shows the final message received by the administrator of the total votes casted and the winner of the election, this way we would save a lot of time and manpower. Since the system is completely automated there is absolutely no human intervention, this resolves one of the major disadvantages of the current EVM's.

21447
Thanks for Voting ABC
ABC:1 MNO:O PQR:O XYZ:0
ABC WON
ABC:1 MNO:1 PQR:O XYZ:0
Result Tie
18325
Thanks for Voting XYZ
ABC:O MNO:O PQR:O XYZ:1
ABC WON
ABC:O MNO:O PQR:O XYZ:1
ABC WON

Fig 5: Polling result on the voter's mobile display

\section{CONCLUSION}

It is a dream of every country to hold a fair election where a common person can register his or her vote to decide the future of the country. The security of the system and the interest of people must be protected at all costs. This system enables us to secure the voting system in a very fair and unbiased manner, it brings us one more step closer to a fair and secure election, it also would enable real time access and hassle-free election experience for the voters. Due to the merits this system provides the state and central elections can be held on the same day without any hassle. The system can also be installed in any KYC centers where people can access the easily.

\section{REFERENCES}

1. Secured Online Voting System with Aadhaar Linking International Journal for Research in Engineering Application \& Management (IJREAM) ISSN: 2454-9150 Special Issue - iCreate April - 2018. 
2. Biometrically Secured Electronic Voting Machine 2017 IEEE Region 10 Humanitarian Technology Conference (R10-HTC) 21 - 23 Dec 2017, Dhaka, Bangladesh.

3. J. Deepika, S. Kalaiselvi, S. Mahalakshmi, S. Agnes Shifani, "Smart electronic voting system based on biometrie identificationsurvey", Science Technology Engineering \& Management (ICONSTEM) 2017 Third International Conference on, pp. 939-942

4. Development of a Credible and Integrated Electronic Voting Machine Based on Contactless IC Cards, Biometric Fingerprint Credentials and POS Printer 2016 IEEE Canadian Conference on Electrical and Computer Engineering (CCECE).

5. N. S Aranganadhan M. DhineshKumar Praveen kumar A DSanthosh "Embedded System based Voting Machine System using Wireless Technology" International journal of innovative research in electrical instrumentation and control engineering vol. 4 no. 22016 pp. 127130.

6. S. Sridhar CH. Manjulathal "Electronic Voting Machine Using Finger Print" International Journal of Professional Engineering Studies vol. 7 no. 4 pp. 274-277 2016.

7. Mobile Based Facial Recognition Using OTP Verification for Voting System 978-1-4799-8047-5/15/\$31.00c 2015 IEEE.

8. E-Voting System with Physical Verification Using OTP Algorithm, 2015 International Journal of Hybrid Information Technology Vol.8, No.8 (2015), pp.161-166.

9. R. Karpagavani, M. Mangai, D. Meena, E. Poonguzhali, Chitravalavan ., "Aadhaar Identity Based Electronic Voting Machine With Instant Result Announcement", i-manager's Journal on Embedded Systems, vol. 4, pp. 26, 2015.

10. B. Divya Soundarya Sai M. Sudhakar "Biometric System Based Electronic Voting Machine Using Arm9 Microcontroller" IOSR Journal of Electronics and Communication Engineering (IOSRJECE) vol. 10 no. 1 pp. 57-65 2015.

11. D. Krishna "Aadhar Based Electronic Voting System and Providing Authentication" International journal of engineering and advanced technology vol. 4 no. 2 pp. 27-240 2013.

12. R. Alaguvel G. Gnanavel "Offline and Online E-Voting System with Embedded Security for Real Time" International Journal of Engineering Research (ISSN: 2319-6890) vol. 2 no. 2 pp. $76-82$ April 2013

13. B. Gomathi S. Veena priyadarshini "Modernized Voting Machine using Finger Print Recognition" International Journal of Scientific \&amp; Engineering Research vol. 4 no. 5 May 2013.

14. D. Ashok Kumar T. Ummal Sariba Begum "A Novel design of Electronic Voting System Using Fingerprint" International Journal of innovative technology \&amp; creative engineering (issn:2045-8711) vol. 1 no. 1 pp. 12-19 January 2011.

15. M Khasawneh M Malkawi O Al-Jarrah "A Biometric-Secure eVoting System for Election Process" Proceeding of the 5th International Symposium on Mechatronics and its Applications (ISMA08). 2008.

\section{Authors Profile}

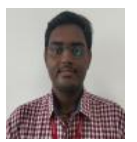

N Prashanth Narayanan Btech ECE SRM IST, graduate with vivid interest in embedded systems and upcoming technologies

Chikkala Surya PradeepBtech ECE SRM IST, graduate with vivid interestin embedded systems and upcoming technologies

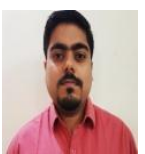

Piyush Gulat Btech ECE SRM IST, graduate with vivid interest in embedded systems and upcoming technologies

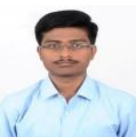

Gollapudi Raj Bharath Btech ECE SRM IST, graduate with vivid interestin embedded systems and upcomingtechnologies

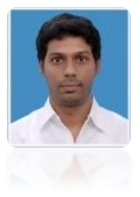

S.Nivash Working as a Assistant Professorin School of ECE, SRM Instituteof science and tec. 